\title{
Religiosidade nos maracatus-nação pernambucanos
}

\author{
Religiosity in maracatu-nations \\ from Pernambuco
}

\begin{abstract}
Alexandra Alencar
Doutora em Antropologia Social -PPGAS/UFSC xanda.alencar@gmail.com
\end{abstract}

Charles Raimundo

Doutorando em Antropologia Social -PPGAS/UFSC charle.301@gmail.com 
Resumo: Este artigo pretende apresentar algumas reflexões sobre a religiosidade nas nações de maracatu de Pernambuco. Tal prática cultural é organizada através dos terreiros de religiões de matriz africana, mas não limitada a eles. Assim os maracatusnação de baque virado possibilitam o diálogo com suas intersecções sociais, artísticas e comunitárias. As nações de maracatu apresentam produções de sentidos - expressas na condução de seu cortejo, na organização social e na forma como os maracatuzeiros pensam e agem - que marcam aspectos da cultura negra. Para tal fim colocamos nossas vivências junto às nações de maracatu pernambucanas em conversas com obras que versam sobre o maracatu-nação e religião.

Palavras-chave: Maracatu-nação; Religiosidade; Cultura negra; Encruzilhada; Sentidos.

Abstract: This article aims to present some reflections on religiosity in maracatu nations from Pernambuco. This cultural practice is organized through terreiros of African-based religions, but not limited to them. As such, the maracatus-nação de baque virado enable dialogue with their social, artistic and communal intersections. The maracatu nations have a production of meanings - expressed in the conduct of their procession, social organization, as well as in how maracatuzeiros think and act - that makes aspects of black culture visible. To this end, we construct a dialogue beteween our maracatu-nation experiences and the literature that deals with the maracatu-nation and with religion.

Keywords: Maracatu-nation; Religiousness; Black culture; Crossroads; Meanings. 
O maracatu-nação pernambucano é uma prática cultural que atualmente está difundida no Brasil e no mundo. Tal prática é atravessada por várias dimensões, entre elas: sua organização em nações - também chamadas de agremiações - em diálogo com instituições do Estado-nação brasileiro; o espetáculo, com apresentações de seu trabalho que dialogam com o mercado de bens culturais e com a indústria cultural; e sua práxis ${ }^{1}$ religiosa vivenciada em rituais e apresentações de maracatu. Essas são algumas possibilidades analíticas, nas quais podemos perceber a negociação de sentidos em que os/as maracatuzeiros/as ${ }^{2}$ reafirmam e recriam suas práticas culturais. Colocados esses apontamentos, este artigo pretende apresentar algumas reflexões sobre as dinâmicas religiosas do maracatu-nação de baque virado em Pernambuco.

Nas apresentações que acontecem geralmente nas ruas, percebemos o maracatu-nação em sua forma de cortejo real ${ }^{3}$, acompanhado de uma estrondosa orquestra percussiva formada por alfaias (bombos), caixas, ganzás e gonguês/agogô. Para além do naipe percussivo apresentado, encontramos nações que utilizam atabaques, agbês e patangomes em sua orquestra. Para um maior detalhamento que apresenta imagens e descrição dos instrumentos ver Alencar (2009). Ao ritmo executado por tal corpo percussivo denomina-se o nome de baque virado. Sendo comum também chamar tal orquestra, ou mesmo uma tocada, entre os/as maracatuzeiros/as, simplesmente de baque. Exemplo: - Onde será o baque amanhã mesmo? Exploraremos melhor o baque virado mais adiante.

A formação deste cortejo, em geral, vem com o estandarte da nação à frente seguido pela corte real e a orquestra percussiva. No entanto, durante o desfile competitivo das agremiações que ocorre no domingo de carnaval no centro do Recife, na passarela adaptada à Avenida Dantas Barreto, a orquestra percussiva vem à frente, entrando a certa altura no chamado recuo que fica de frente ao corpo de jurados, formando uma espécie de corredor onde as outras alas e personagens da corte passam para ser avaliados, assim como a execução musical do baque.

A antropóloga e ex-presidente da comissão nacional do folclore de Pernambuco (PE), a norte-americana Katarina Real (1990 e 2001), utiliza a palavra nação ao se referir aos maracatus considerando dois motivos principais. Um diz respeito à disputa entre os pesquisadores que estudavam tal manifestação e as conceitualizações e significados em torno da palavra maracatu, como Guerra-Peixe (1980) e Mário de Andrade (1959). Outra 
justificativa situa-se na opinião de Veludinho, batuqueiro lendário que fez parte dos centenários Maracatu Elefante (fundado em 1800) e Leão Coroado (fundado em 1863), sendo ele mesmo um centenário - morreu com 107 anos e tocou até os 103 um bombo mestre. Segundo Veludinho, citado por Real, o nome "maracatu" foi uma invenção de "homens grandes", afirmando categoricamente que "o nome era nação" (REAL, 1990, p. 58$)^{4}$.

Hoje encontramos uma gama de trabalhos acadêmicos que versam sobre a noção de nação desenvolvida sobre tal manifestação e pela maneira como os/as maracatuzeiros/as conceituam sua prática cultural. Segundo Carvalho (2007), a nação aponta para um caráter mais restrito e enraizado numa comunidade (social e religiosa). Ampliando um pouco mais essa ideia, de forma sistemática, Lima (2013) propõe que o maracatu-nação se define por seu território, religião, práticas compartilhadas e espetáculo coletivo. Tal nação remete aos laços com o xangô pernambucano ${ }^{5}$, com a forte ideia de africanidade subjacente à identidade afro-brasileira, como também à religião da jurema ${ }^{6}$ e, nesse sentido, "a técnica estreitamente musical do maracatu de baque virado é mais aberta ao trânsito” (CARVALHO, 2007, p. 35).

No entanto, o exemplo do Maracatu Porto Rico de Recife parece-nos interessante para ampliar a noção de nação até aqui desenvolvida. Tal nação possui sua extensão para além de Pernambuco, através "dos filhos da nação", expressão empregada pelo mestre da mesma nação, Chacon Viana, referindo-se aos grupos e seus membros que tocam apenas a nação Porto Rico e que têm nele seu mentor espiritual e musical. Os "filhos da nação" - expressão comum nos terreiros de candomblé - encontram-se espalhados pelo Brasil e pelo mundo. Assim restringir demais tal noção a Pernambuco, acaba nos levando a reduções analíticas no mínimo simplistas. Não queremos nos alongar por hora nesta questão, porém nos parece que tal fenômeno etnográfico nos leva a (re)considerar a comunidade e o território das nações de maracatu enquanto restritas ao bairro de origem, pois há um movimento de levar suas ações para uma amplitude nacional ou mesmo internacional.

Em nossa experiência ao longo dos anos junto ao maracatu de baque virado compreendemos que a ideia de nação é fruto da experiência dos/as maracatuzeiros/as no tempo, conferindo dinamicidade a esta prática cultural, pois existe uma questão contingencial, referente às pessoas que fazem a nação em determinado período, seja nos 
dias atuais ou na sua fundação. As nações são experiências vivas, logo, dinâmicas que equilibram passado e presente, tencionando uma memória dos mais velhos com as aspirações e inovações dos mais novos, algo próximo ao que os autores Edimilson Pereira e Núbia Gomes apresentam como tradição nostálgica e tradição de princípio na organização de reinados negros em Minas Gerais (PEREIRA \& GOMES, 2000). Nessas dinâmicas encontramos o sentimento de pertença a uma comunidade de prática e de sentidos que passa pelo terreiro - principalmente de nação nagô, mas não restrito a esta enquanto aglutinador dessas referências. Estas referências passam por uma lógica própria das religiões de matriz africana, simultaneamente organizando origem (ancestrais, orixás, África) e possibilitando transformações (dinâmica das nações e suas atualizações) (GOLDMAN, 2011).

Inerente à nação de maracatu está o baque virado, a força sonora propulsora do cortejo enquanto melodia e ritmo. Efetuada por batuqueiros/as, produz a base para que maracatuzeiros/as das nações cantem e dancem suas toadas. Tais toadas - também conhecidas como loas - são estruturadas, em geral, num jogo de pergunta e resposta, onde o mestre de apito ou rainha puxam a toada e o restante do cortejo responde a sua iniciativa fazendo o que se costuma chamar de coro, podendo ser a resposta igual ao que foi cantado na primeira voz ou diferenciando um pouco do que foi pronunciado. Nas letras podemos perceber diferentes relações, temporalidades e preocupações. Encontramos em seus versos culto à ancestralidade, contextos em que é feita e de como é feita essa prática cultural, além de sua referência explícita e/ou implícita à religião dos orixás.

Pergunta: No brilho da noite em Palmares ouvi/ A batida forte do tambor

Resposta: No brilho da noite em Palmares ouvi/ A batida forte do tambor

P: É festa, orixá desceu à terra/ A nação nagô espera mensagens que vem de Olorún

R: É festa, orixá desceu à terra/Com a força do baque virado nação Porto Rico fazendo darrun

P: Xangô é rei, Iansã minha rainha/ dama do paço, calunga em seus braços, meus ancestrais eu vou louvar

R: Xangô é rei, Iansã minha rainha/ 100 anos de resistência noite do dendể vai ecoar.

Dentro deste escopo, no cortejo real do maracatu e suas louvações gostaríamos de ressaltar, para os fins deste trabalho, a centralidade de uma personagem: a Calunga. Boneca de aproximadamente $60 \mathrm{~cm}$, podendo ser de madeira, cera ou pano, vestida, com 
igual esmero, como a dama de paço que a carrega. Flutuando sobre as cabeças em cortejo, a calunga vem dançando com a dama de paço, que declara pela sua presença, para aqueles que conhecem os segredos da religião do xangô pernambucano, a referência a uma ancestralidade, aos eguns ${ }^{9}$ de outros tempos, de outros carnavais. Segundo mestre Afonso Aguiar do maracatu-nação Leão Coroado, ela é uma das principais forças dentro do cortejo de maracatu e estaria no alto da hierarquia da corte..$^{10}$

(...) a história da calunga é meia complicada, porque é a parte da ancestralidade, é a parte do candomblé que trabalha com os eguns, e não é todo mundo que conhece... A rainha é uma figura importante. Agora, só que ela tem que saber que na frente dela tem uma figura mais importante que é a calunga e a dama do paço que segura ela. Então é quem manda.

Além do culto aos ancestrais, através da calunga, a força sonora propulsora do baque virado e o canto das toadas que demonstra diferentes relações, temporalidades e preocupações é preciso mencionar a forma como essas nações sobrevivem financeiramente. Para além do carnaval, tais nações realizam apresentações em eventos públicos, organizados pelo Estado de Pernambuco, prefeituras municipais e ainda, em menor grau, para a iniciativa privada, onde ganham cachês que financiam parte de suas práticas. Tais eventos mostram o trabalho das nações de maracatu realizado por suas comunidades e entidades sob a forma de um espetáculo e produto a ser consumido no mercado de bens simbólicos, sendo este produto apenas a ponta do iceberg do trabalho interno das nações de colocar o maracatu na rua, sua luta diária por reconhecimento e, sobretudo, os sentidos que esses maracatuzeiros/as atribuem à sua prática cultural.

\section{O maracatu-nação como produção de sentidos e fonte de estudos}

As nações de maracatu, se não estão vinculadas diretamente a algum terreiro de matriz africana, ou seja, sediadas dentro desses espaços religiosos - terreiros que em sua maioria são de candomblé de nação nagô - como é o caso da Nação de Maracatu Encanto do Pina (sediada no Ilê Axé Oxum Deym), fazem suas obrigações ${ }^{11}$ nestes lugares, como é o caso da Nação de Maracatu Leão Coroado, da Nação de Maracatu Estrela Brilhante do Recife, dentre outras, para que os trabalhos da nação de maracatu ${ }^{12}$ aconteçam de forma segura, sem obstáculos ou infortúnios quando esta sai às ruas. Nesse sentido por ser o maracatu-nação integrante de terreiros em Pernambuco, seus movimentos, fluxos, alianças e resistências assemelham-se muito, para não dizer caminham junto, aos acontecimentos que afetaram as religiões de matriz africana, seus 
terreiros e suas práticas ao longo dos séculos XIX, XX e XXI (para um maior aprofundamento da relação entre terreiros e nações de maracatu temos as obras de Guerra-Peixe (1980), Andrade (1959), Real (1990), dentre outras).

Neste ponto podemos encontrar paralelos, ecos, histórias, registros quanto às posturas e estratégias de manutenção das nações e seus baques virados que trabalham pela noção de tradição imutável, um balanço entre a tradição nostálgica e a tradição por princípio (PEREIRA \& GOMES, 2000). Como exemplos, temos a nação Estrela Brilhante de Igarassú, na qual até hoje as mulheres não tocam tambores e homens não dançam, ou mesmo Leão Coroado, na qual há uma preocupação de manter o mesmo baque que foi criado pelo mestre Luiz de França ${ }^{13}$; e as nações Estrela Brilhante do Recife e Porto Rico que ao longo dos anos incorporaram novos instrumentos e jeitos de se vestir. Assim, há uma disputa pela autenticidade e pureza de seus rituais e baques.

Para avançarmos mais na relação maracatu/terreiro de Xangô, procuramos trazer um pouco desta trajetória, através de uma literatura sobre as religiões de matriz africana e o maracatu-nação de baque virado, percebendo o quanto podemos explorar nesta as relações maracatu/terreiros. Dentro desta produção iniciamos a reflexão com a busca por uma pureza, ou verdadeiro ritual, em contraponto às degenerações destas. Nas obras anteriores à década de 1970 o contexto se refere à pureza africana nos candomblés, fomentando no meio intelectual a procura pelos detentores da verdadeira religião afro no Brasil: Bastide (1971), Santos (2012), Rocha (1994), Guerra-Peixe (1980). Tais análises geram alguns binarismos como puro/degenerado, nordeste/sudeste-sul, resistência/mistura, negro/branco, nagô/outros etc. Como crítica a esta abordagem teórica, Dantas (1988), Maggie (2001), Capone (2009), exploram os usos de África nas religiões de matriz africana e as disputas intelectuais em torno delas.

Podemos verificar diferentes abordagens, que tentam à sua maneira entender a África, o Brasil, a trajetória do negro no Brasil e suas mazelas através da religião. $\mathrm{Na}$ amplitude dos argumentos encontramos análises evolucionistas (PEREIRA DA COSTA, 1908; RODRIGUES, 1932), nacionalistas (FREYRE, 2003; GUERRAPEIXE, 1980; ANDRADE, 1959), psicologistas (SEGATO, 1995), sociológicas (BASTIDE, 1971), demonstrando continuidades e rupturas, conflitos e linguagens entre África e Brasil, entre Brasil e Brasil (MAGGIE, 2001; SANTOS, 2012; CAPONE, 2009; DANTAS, 1988; TRINDADE-SERRA, 1995). Realizamos esta digressão para 
apresentar algumas obras e temas relevantes para o estudo das religiões de matriz africana no Brasil que influenciam na criação e manutenção das nações de maracatu até a atualidade.

Outro interessante debate a respeito das diferenças e estratégias em torno do uso dos termos afro-brasileiro e negro, seus usos e preconceitos velados pode ser visto em Maggie (1975), Dantas (1988) e Lima (2005). Nesse sentido, a valorização ideológica da África poderia servir como índice de preconceito contra o negro. A África estaria distante, sendo os negros estrangeiros. A passagem de estrangeiros para brasileiros negros, de pele escura é que se torna um problema, optando-se no inicio do século XX pela diluição do negro no branco. Além do que, a palavra negro torna-se sinônimo de depreciação - magia negra, denegrir, mercado negro, entre outras - expressando racismos de linguagem arraigados e naturalizados. Pela trajetória de africanos e seus descendentes no Brasil, optamos ao longo do trabalho o uso do termo negro/a, porém não descartamos o termo afro-brasileiro/a, justamente por acreditar que esse representa africanidades no Brasil.

Dito isto, gostaríamos de realizar um breve exercício de apresentar um panorama sobre intenções e estudos do maracatu-nação de baque virado. Através dos estudos de folcloristas do início do século XX, como em Pereira da Costa (1908), Varejão (1991), Sette $(1938 ; 1948)$ percebemos que o maracatu é apresentado como uma manifestação cultural do passado escravocrata. Tais autores acionaram interpretações sobre o suposto desaparecimento das manifestações dos escravizados e seus descendentes. Esta tendência interpretativa coaduna-se com as teses racialistas que vigoravam na mesma época, da inferioridade racial e dos efeitos supostos da miscigenação como capaz de deflagrar um processo de branqueamento de povos e culturas.

O médico legista Nina Rodrigues (1932) desenvolve esse tema, defendendo uma postura de não repressão aos cultos (africanos) e ao mesmo tempo, vendo na extinção do negro no Brasil uma necessidade pelo seu atraso moral e intelectual. O trabalho de Nina Rodrigues é pioneiro no estudo etnográfico sobre populações africanas no Brasil e suas manifestações culturais. O livro Os africanos no Brasil apresenta uma ambigüidade: por um lado relaciona o atraso da civilização brasileira por estar na base de sua configuração o elemento africano, índio e o próprio português (o pior entre os 
europeus); e por outro, defende os cultos africanos mais puros, em especial o nagô de Salvador, sua riqueza cultural, demonstrando através do direito jurídico (Constituição) que os ataques deferidos aos terreiros eram totalmente descabidos e autoritários, o que dificultava ainda mais nosso ingresso em uma civilização mais evoluída. Esse esquema aparentemente contraditório acionava uma perspectiva evolucionista e uma glorificação da pureza primitiva africana. Cabe lembrar que este interesse pela religião dos africanos no Brasil estava vinculado à comprovação da inferioridade racial do negro.

Em 1933, Gilberto Freyre publica Casa-Grande \& Senzala, análise da formação da sociedade brasileira com base no encontro das três raças, o qual dá origem à ideologia do Brasil-cadinho. Esta ideologia logo se torna mito fundador do Estado brasileiro moderno e a fonte de outro mito fundador: a democracia racial (CAPONE, 2009). A obra retoma o tema da convivência entre as três raças, a partir da abordagem culturalista de Franz Boas, do qual foi aluno, mas não fala de conceitos de superioridade ou inferioridade, nem fala da violência presente no período escravista. Dessa forma, a miscigenação aparece como sinônimo de tolerância e hábitos sexuais de intimidade que se transformam em modelos de sociabilidade.

Os parágrafos anteriores apresentam certos fatores que interferem na história dos maracatus-nação, pois no período do Estado novo (1937 a 1945), em meio à intensa repressão aos maracatus e às religiões de matriz africana em Pernambuco, intensificada na interventoria de Agamenon Magalhães, houve um movimento de mediação cultural que alçou os maracatus-nação do lugar de coisas de negro com provável desaparecimento, para o lugar de cultura autenticamente pernambucana. Esse movimento de mediação cultural foi responsável por atiçar um novo interesse, aguçar o olhar dos intelectuais. Para Guillen (2013), tais mudanças de paradigmas contribuíram para que a cultura e as práticas culturais começassem a ser pensadas pela ótica de quem as praticava.

Mário de Andrade estudou os maracatus em seu livro Danças dramáticas, escrito entre 1934 e 1944. O texto publicado, em parte apresentado no I Congresso AfroBrasileiro no Recife, ao final do ano de 1934, teve como objeto de discussão as calungas. As diferenças entre Pereira da Costa e Mário de Andrade sinalizam que, para este último, era fundamental adentrar o universo das culturas populares com um olhar etnográfico, até para contrapor uma identidade nacional pautada apenas na cultura regional carioca e paulista. 
Na esteira de Mário de Andrade, muitos outros folcloristas e etnógrafos escreveram e publicaram pequenos estudos sobre os maracatus, a exemplo de Roger Bastide, em Imagens do Nordeste mistico em branco e preto, de 1945. Outra visão sobre a cultura popular entrava em circulação entre esses intelectuais. E dentro desse contexto, o estudo de maior impacto já feito sobre os maracatus no período foi o de César Guerra-Peixe.

A obra de Guerra-Peixe, Maracatus do Recife, publicada em 1955, foi por muito tempo considerada como o estudo mais completo sobre os maracatus, com uma vasta pesquisa de campo, da qual resultou a categorização dos dois tipos de maracatu existentes em Pernambuco: o maracatu-nação, maracatu urbano ou de baque virado, e o maracatu de orquestra, rural ou de baque solto.

Quando o maestro Guerra-Peixe (1980) realiza sua pesquisa sobre o maracatunação de baque virado em Recife nos anos 1949 a 1952, com especial atenção ao Maracatu Nação Elefante (fundado em 1800) da Ialorixá e Rainha Dona Santa realiza, talvez, a primeira obra com maior preocupação de se registrar o maracatu como era feito, em certa medida se aproximando ao método etnográfico ${ }^{14}$. Apesar de uma linguagem preocupada com a extinção, ocupava-se em mostrar com aproximação total do verdadeiro, criando registros de toadas e notações musicais em partituras de simbologia das escolas européias. Infelizmente, Guerra-Peixe, apesar de nos informar que trabalha diretamente com as nações, tendo informantes - este é o termo que utiliza - diretos e super colaboradores, parecia ainda continuar com uma ideia de investigação que colocava em segundo plano a opinião dos/as maracatuzeiros/as sobre sua própria cultura, além de muito pouco identificar quais eram seus informantes - a exceção seria Gobá, que segundo suas palavras, era o informante mais valioso da pesquisa e um dos melhores músicos de xangô. Outro ponto é sua excessiva catalogação e instituição de verdades sobre o maracatu, algo que estanca, congela a dinâmica e diversidade desta prática cultural. Seu método, ao menos é a impressão que fica, é de generalizar o particular, no caso, o Maracatu-Nação Elefante como verdadeiro representante do maracatu.

Apesar de suas limitações, não podemos deixar de assinalar a menção que faz do quão difícil é se registrar o maracatu por sua complexidade de sentidos e contextos simbólicos e rituais - imbricados em suas partituras sonoras. Em seu projeto de cunho musical nacionalista, elabora um documento respaldado por um grupo de sinceros e dedicados 
informantes, que colaboraram com anotações que escapam à alçada de um músico, contribuindo dessa forma para completar as explicações em torno da funcionalidade do maracatu. Mesmo com a intenção de classificar, catalogar os maracatus, em certa medida tal autor registra a história do povo do maracatu. Isto não implica, no caso do maestro, o abandono da posição de intelectual com que se dirige ao povo pobre com certa arrogância, etnocentrismo, objetificação e autoridade. Podemos ver essa atitude na sua passagem sobre a dama do paço (GUERRA-PEIXE, 1980, p. 40).

Dentro dos estudos do maracatu e sua relação com a religião, seria incorreto não trazermos outro texto de Katarina Real (2001), na qual a autora escreve sobre o Maracatu Porto Rico do Oriente, enfatizando o papel desempenhado pelo Rei Eudes Chagas junto a essa nação e comunidade. Real deixa pistas sobre a importância e relevância das práticas religiosas referentes ao maracatu-nação. Ao propor a ajudar na criação deste maracatu na segunda metade do século XX - fato que ela traz com muita euforia, pois, assim como Guerra-Peixe, acreditava na possível extinção das nações africanas - nos traz excelentes momentos da vida de um maracatu e seu contingente. Apesar do trabalho informar mais sobre a autora e suas reflexões sobre o maracatu, se ajustarmos nossa leitura, no sentido de perguntar ao Porto Rico e ao rei Eudes nossas inquietações sobre o maracatu e suas estratégias negras de concretizar tal prática, realizada por comunidades de maioria negra da periferia, perceberemos a inteligência e sagacidade do povo de santo em ludibriar as autoridades repressoras, pois através de seus maracatus, louvavam os seus orixás e ancestrais. As festas realizadas por Eudes na sede da nação, no Bairro do Pina, são excelentes demonstrações dessa astúcia. O depoimento do Rei e Babalorixá Eudes Chagas, nas páginas 21 e 22 da obra, é excelente para pensarmos este aspecto.

Dessa forma, se por um lado Katarina Real contribuiu para o surgimento de um maracatu, seu interesse está vinculado à ideia de desaparecimento de tal manifestação, (re)afirmando que os maracatus-nação são de origem africana e que se não forem realizadas intervenções, estão fadados ao desaparecimento, ou seja tais prática culturais precisariam ser salvas. Resumidamente o enfraquecimento das nações na década de 1960 e parte dos anos de 1970, para tal autora, devia-se à desintegração de duas pedras fundamentais: o orgulho da herança mais ou menos "africana" e a desintegração do "matriarcado" afro-brasileiro (REAL, 1990, p. 68). Por ora nos limitamos a dizer que nossas observações sobre o maracatu e suas memórias apontam na direção oposta à 
proposta pela autora, tanto que hoje na história das nações de maracatu temos rainhas, que exercem seu matriarcado e religiosidade, a exemplo da Rainha e Ialorixá Elda Viana do Maracatu Porto Rico, que mostra a força da mulher no terreiro ao longo do século XX e o papel das rainhas na atualidade como força central em muitos maracatus.

Contudo, o que temos de questionar é que salvação é essa, se é que os/as maracatuzeiros/as precisavam ser salvos, pois existiam e existem até hoje, passando por momentos históricos de perseguição. Em outras palavras, os maracatus existem independentemente das ações desses intelectuais, por mais que devam ser reconhecidas as alianças e estratégias junto a estes.

Mas é no compasso das ideias de desaparecimento e necessidade de salvação que, nas décadas de 1970 e 1980, o maracatu-nação continuará a ser representado como uma reminiscência africana, principalmente nos escritos de Roberto Câmara Benjamin e Leonardo Dantas Silva. Para tal mudança conjuntural era preciso um momento de grande visibilidade dos maracatus-nação no cenário cultural pernambucano, brasileiro e mesmo mundial - mas também, nos termos de Isabel Guillen (2013), "um novo olhar que desconstruísse as já tão consolidadas visões que circunscreviam a manifestação cultural como tradição imutável” (GUILLEN, 2013, p. 21).

No início dos anos 1990, a cena cultural no Recife parecia passar por transformações significativas. Ariano Suassuna ${ }^{15}$ assumiu a Secretaria de Cultura no governo de Miguel Arraes, entre os anos de 1995 e 1998, fomentando intensa discussão sobre a cultura popular, identidade pernambucana e políticas públicas voltadas para elas. Nem todos concordaram com os rumos que essas políticas públicas buscavam imprimir na cena cultural pernambucana; tensão expressa pelos mangueboys, tanto Chico Science, quanto Fred 04 - músicos de origem pernambucana, com carreiras internacionais, que ganharam a cena da música nacional entre as décadas de 1990 e 2000.

Se, para um segmento, os maracatus-nação significavam o cerne da tradição e da cultura popular, para os idealizadores do Movimento Mangue Beat, a batida do maracatu permitia conectar "com uma parabólica fincada na lama"16 o local e o global. Assim a linguagem musical e as nações de maracatu tornaram-se conhecidas no Brasil e no mundo, gerando a criação de muitos grupos percussivos, a exemplo do Maracatu Arrasta Ilha em Florianópolis ${ }^{17}$ (ALENCAR, 2009). Esta conjuntura teria proporcionado 
interesse e criado legitimidade para a entrada da classe média nos maracatus-nação, fazendo emergirem questões que seriam objeto de teses e dissertações em diversas áreas das ciências humanas. Muitos desses trabalhos foram desenvolvidos por pessoas que participaram de grupos de maracatu ou mesmo das nações de maracatu pernambucanas e trataram de explorar aspectos bastante diversificados, em várias áreas de pesquisa como Lima (2005), na área da história; Barbosa (2001), Barbosa (2001) e Carvalho (2007), na área da etnomusicologia; Lara (2004), na área da educação; Santana (2006) e Ferreira (2012), na área da geografia; Kolinski (2011), Kubrusly (2007), Oliveira (2011), Alencar (2015) e Leal (2008), na área da antropologia, entre outros.

\section{As práticas religiosas e atribuição de sentidos no maracatu-nação}

Dentro deste amplo quadro de estudos realizados através dos maracatus e os sentidos produzidos pelos/as maracatuzeiros/as, conduzimos agora nosso olhar para aqueles que expressam o maracatu enquanto religião por meio de suas vivências. Pessoas que têm sua fé estampada nas roupas, nas toadas e ritmos de seus sons, na apresentação de seus desfiles e toda sua realeza. A corte real é lugar de encontros entre o ayê e o orun ${ }^{18}$, encontros que se estendem para além das apresentações, que têm seus contornos ampliados para o pré e pós desfile/apresentações, onde há organização comunitária, centralizada no terreiro e na nação. Tais vivências colocam em evidência a presença de diferentes entidades espirituais (orixás e eguns) relacionadas aos seres vivos, mobilizando todo um aparato ritual religioso para dar segurança, força e vitória, tendo maior intensidade quando próximo ao carnaval. Do corte a corte, diferentes agentes são colocados em interação. Para alimentar a nação é preciso conhecer seus caminhos, saber as necessidades materiais e imateriais, essas apontadas na comunicação pelos búzios e seus correspondentes trabalhos posteriores. Ir à rua com um maracatu significa uma serie de precauções e tributos, que movimentam o processo ritual (TURNER, 2013) do maracatu em performance (BAUMAN \& BRIGGS, 1990).

Nesse sentido existe uma contribuição importante da religião afro-brasileira aos saberes e fazeres, psicológicos, pedagógicos, artísticos, espirituais, culturais na concepção de uma pessoa humana. Uma contribuição que transcende a retórica litúrgica apelativa e eficaz, constituindo-se como "um corpus teórico sofisticado de difícil aprendizado e em constante elaboração e discussão" (SEGATO, 1995, p. 16). Tendo isso em mente, em nossa própria vivência enquanto maracatuzeiros/as compreendemos 
esses espaços, as nações, como verdadeiras escolas negras. Escola aqui não no sentido oficial de instituição ligada ao sistema educacional do Estado, mas como potência de agregação e transmissão de conhecimentos que apesar de suas intersecções com o Estado, organiza-se e desenvolve ações onde sua tradição passa pelo terreiro, pela religião, pelos tambores e pela oralidade.

Nesta direção, a cultura negra/afro-brasileira enquanto estratégia, enquanto principio organizador envolve aspectos religiosos, sonoros, corporais, dentre outros onde a circulação de conhecimentos e práticas configura alianças e tensões. Queremos com isso dizer que há uma tessitura de relações nas nações de maracatu, presente nos processos diários, principalmente por volta do carnaval (mas não limitado a ele), onde as agremiações se preparam para um momento pleno de seu trabalho - trabalho de colocar o maracatu na rua para fazer o carnaval.

Quando dialogando com as religiosidades presentes na cultura negra, a encruzilhada aparece como metáfora rica de possibilidades e plasticidade de ação (MARTINS, 1997), onde existem caminhos nas mais diferentes direções, o que torna as práticas culturais negras um constante devir (DELEUZE \& GUATARRI, 2011). E se é nos cruzamentos e rua que acontece o maracatu-nação, nos quais observamos cada vez mais diferentes direções e processos criativos de produção de sentidos sobre esta prática cultural, não surpreende o fato de que Exú seja uma das entidades principais a ser alimentada antes de uma apresentação, ou como coloca mestre Chacon Viana da Nação Porto Rico, a principal entidade do carnaval. Enquanto princípio dinâmico (SANTOS, 2012) de natureza ambivalente, tal entidade pode ser bondosa para aqueles que não se esquecem de sua força, como também pode ser maldosa com aqueles que a esquecem ou a tratam de maneira equivocada.

Outras entidades a serem consideradas são os eguns, representados pela calunga, que precisa ser alimentada e tratada, através de rituais religiosos, garantindo assim a tranquilidade da nação. Segundo o mestre e babalorixá Afonso Aguiar do Maracatu Leão Coroado, se mal tratados, os eguns podem por o maracatu a perder ${ }^{19}$. Entram nessa negociação bodes, galinhas, pintos entre outros sacrifícios animais, em forma de ebós ${ }^{20}$.

Assim tomamos a encruzilhada como valor significativo às religiosidades afro- 
brasileiras e por conseguinte aos maracatus-nação pernambucanos. Nestes caminhos cruzados, abertos ou fechados, cursos componentes de um território existencial. Assim os caminhos da vida devem estar (des)impedidos por obstáculos espirituais. Muito além de uma simples metáfora entre vidas e caminhos, temos o pensamento que faz a vida um território a se percorrer (ANJOS, 2006). Nesses espaços/territórios a vida não se limita ao tempo presente. Mais que o aqui e agora, as relações que envolvem o terreiro, o maracatu com seus rituais estendem-se ao passado, ao futuro e a outros planos que não o material.

Para Wulf (2013), os rituais e gestos criam comunidades. Sem rituais, não haveria o social. Nos maracatu-nação há vários rituais que perpassam a prática como as obrigações religiosas para tambores, calungas e muitas vezes banhos de amaci para os/as maracatuzeiros/as, tudo isso com o objetivo de trazer proteção. Assim, "rituais são encenações e representações de relações sociais. Seu caráter performativo emerge. Eles tornam algo visível, que sem eles não existiria. Rituais projetam passagens de um status sociais para outro e desdobram assim uma força mágica" (WULF, 2013, p. 15).

Em nossas experiências etnográficas com nações e maracatuzeiros/as em Pernambuco, entendemos que as religiosidades, enquanto trama dessas comunidades de práticas, produzem efeitos oriundos de processos contendo lógicas próprias de ação, evocados em suas linguagens estéticas, corporais, orais e musicais, aguçadas por suas memórias, o legado ancestral, a presença criativa. Concepção ligada a um lidar com o mundo que tem suas conversas com África, desde o advento da diáspora para as Américas.

Tais maracatuzeiros/as, através das suas diversas experiências rituais, constroem uma cosmologia própria que orientam suas formas de agir no mundo, ainda que muitas vezes sua forma de agir no mundo seja a de colocar tal relação religiosa do maracatunação no plano do secreto, como é o caso da Nação de Maracatu Estrela Brilhante de Igarassú. Segundo Gilmar Santana, mestre desta nação de maracatu, a parte religiosa é feita, mas não é assunto para ser divulgado para quem vem de fora e deseja conhecer e aprender o maracatu desta nação. A preocupação dessas pessoas deve ser muito mais com aspecto da brincadeira que tal prática cultural oferece.

Diferentemente no Ilê Oxóssi Guangoubira, componente do complexo que abarca também a sede da Nação de Maracatu Porto Rico, coordenado pela rainha e 
ialorixá Elda Viana pudemos acompanhar alguns rituais do terreiro, onde ocorrem encontros dos filhos de santo da casa, mas também abertos, em sua maioria, ao público que deseja assistir. Nesses rituais há uma presença muito grande dos/as maracatuzeiros/as. Durante os encontros, os ogãs ${ }^{21}$ posicionam-se junto aos tambores para tocá-los e os filhos de santo da casa, vestidos de branco, se organizam em roda. A ialorixá Elda Viana, seguida de outros membros do Ilê, soltam zuelas (cantorias) em iorubá ao som dos ilús e atabaques ritmados. O canto segue uma ordem que vai de Exu a Orixalá - xirê. Os pontos podem ser cantados em jejê ou nagô, que seriam as duas nações de candomblé, que traçadas dão a orientação religiosa deste terreiro.

Se cantados no nagô, os ogãs tocam nos ilús ${ }^{22}$. Se cantados no jejê, os ogãs sobem a uma espécie de palco que tem no terreiro e tocam nos atabaques com aguidavis (varetas). Durante este ritual, os médiuns da casa fazem pequenos movimentos corporais que lembram as características arquetípicas de cada orixá, a exemplo do espelho que remete a beleza de Oxum, ou a flecha que remete ao caçador Odé. Dependendo dos filhos de santo que estejam na casa, pode acontecer a incorporação para determinados orixás. Também podem ocorrer incorporações de pessoas que estejam assistindo, e estas são conduzidas com um pano branco amarrado na altura do tronco até a roda dos filhos de santo para trabalhar com os orixás. Caso essas pessoas possuam nos bolsos celulares, carteiras e outros objetos, esses são retirados antes de serem conduzidas até a roda no centro do salão. Nessas sessões também observamos alguns filhos de santo entregando comidas para determinados orixás. Depois de cantado para Orixalá o ritual se encerra, alguns médiuns ficam em frente ao terreiro ou mesmo dentro do Barracatu ${ }^{23}$ bebendo e conversando, outros vão embora direto, mas depois todos retornam para suas casas.

Para Motta (2000), o xangô pernambucano relacionado ao culto dos orixás possui uma prática ritual centrada em torno do sacrifício (obrigação) e do transe que, ao menos no plano do tipo ideal, assume a forma de êxtase. Sua organização se caracteriza em torno de um terreiro e de um sacerdócio, representado por babalorixás e ialorixás, cujo acesso é em terreno reservado aos que passaram por um processo específico de iniciação ou ordenação.

Assim, através desses breves relatos etnográficos sobre práticas religiosas, realizadas nos terreiros, nas quais estão inseridos muitos dos/as maracatuzeiros/as das 
nações pernambucanas, podemos experienciar sua fé, e nesse sentido compreender, ainda que muito superficialmente, de que forma o maracatu se expressa em religiosidades.

\section{Considerações Finais}

Verificamos ao longo deste trabalho que o maracatu-nação de baque virado apresenta dinâmicas culturais diversas e diversamente analisadas por pesquisadores e artistas, assim como os próprios maracatuzeiros/as e suas nações produzem formas próprias de contar sua história.

O maracatu enquanto dimensão religiosa catalisa esses elementos na organização de seu sistema conectivo, de entrelaçamento, que atribui sentidos a suas práticas, ações e narrativas. Neste caminho poderíamos ainda levar em consideração a religião e seus respectivos rituais em cada nação como marcador de diferença. Assim como a religião também distingue o maracatu-nação e os grupos de maracatu de baque virado. Por tal motivo a condição de maracatu-nação estaria necessariamente vinculada a uma articulação direta com um terreiro. Mas a fronteira baseada no ter ou não a religiosidade dentro do maracatu também é tênue, pois muitos grupos de maracatu estão criando laços religiosos diversos para o desenvolvimento da prática do maracatu. Essa referencia à religiosidade torna-se algo distintivo para os maracatus-nação e ao mesmo tempo objeto de desejo de alguns grupos que buscam uma prática com maior fundamento.

Neste contexto, as lideranças, figuras que articulam a comunidade de santo e o povo do maracatu, promovem intersecções ricas na compreensão desta relação. Um exemplo disso pode ser observado no depoimento de Mestre Chacon Viana da Nação de Maracatu Porto Rico quando ele fala da responsabilidade dos grupos de maracatu espalhados pelo Brasil e pelo mundo frente à manifestação cultural do maracatu-nação:

É você estudar, não é só tocar. Ir buscar sua herança, buscar suas raízes, ver a história de cada uma, ou o que toca, se não for cada uma, mas pelo menos uma base de duas ou três nações que toca, respeitar a questão dos tambores, tentar dentro de cada data, no aniversário do maracatu, fazer um banho de amaci pra todo mundo. Porque não há nada de mais em um banho de amaci. Então essas coisas pequenas que se dá o 
respeito, que a gente dá grande importância. Não existe mais viver longe da religiosidade. Vocês estão dentro da religiosidade todo momento. Vocês tão tocando maracatu, a religiosidade está com vocês em todo o momento. Então vocês podem estar no Japão, mas ela tá presente. Na hora que você toca, você evoca. Na hora que você canta, você também saúda. Seja lá onde for, os orixás e eguns estarão junto com vocês, independente de qualquer momento, qualquer hora, qualquer lugar. Então maracatu é isso aí, não tem como fugir de perto ou longe, grande ou pequeno, tudo é maracatu, e tudo requer uma importância baseada na religiosidade que você não imagina. (Entrevista concedida em setembro de 2012).

Na religiosidade afro-brasileira traçada com o maracatu-nação pernambucano perpassa, em forma e conteúdo, os/as maracatuzeiros/as em seus fazeres e quereres. É essa dimensão que torna o maracatu-nação uma configuração cultural fértil na produção de sentidos articulados em contextos e situações sócio/culturais situadas no presente, mas que articulam ao mesmo tempo passado e futuro.

\section{Notas}

1. Práxis aqui é entendida como o trabalho conjunto entre reflexão e ação. Podemos encontrar alguns exemplos dessa proposição: na antropologia em Langdon, (1999), ou mesmo na educação em Freire (1996), em que o conhecimento não está flutuando separado de uma ação.

2. Utilizamos o termo maracatuzeiro/as como o conjunto de pessoas que constroem a nação de maracatu, envolvendo toda corte imperial, mas não se restringindo a ela - costureiras, apoio, fotografia etc. - pessoas que ocupam diferentes funções durante as apresentações e antes destas. Este termo é corrente nas nações, assim como nos grupos de maracatu.

3. Cabe lembrar que o maracatu tem sua coroação de reis e rainhas, originárias das coroações dos Reis do Congo e das Irmandades de Nossa Senhora do Rosário, prática que data do século XVII, mostrando também a intersecção com a igreja católica. Tal instituição não é exclusiva do maracatu. Podemos encontrar também em cacumbis e congadas, por exemplo. Sobre a coroação de reis negros de ontem e de hoje ler Pereira da Costa (1908), Ferreira (1951), Silva (1994) apud Reis (1996). Contudo, Lima (2005) traça a relação linear entre os Maracatus-Nação e os Reis do Congo enquanto duvidosa, pois aponta dados históricos para a contemporaneidade de maracatus e congos no século XIX, não sendo necessariamente um decorrência do outro.

4. Para localizar o leitor, achamos necessário mencionar a existência de dois tipos de maracatus em Pernambuco, diferentes na sua trajetória, forma e conteúdo. São eles o maracatu-nação de baque virado e maracatu rural ou de baque solto. Por isso a importância de se encontrar traços diacríticos dessas manifestações homônimas.

5. Xangô seria uma espécie de variação local do candomblé. Não necessariamente nas mesmas aplicações rituais e míticas que os candomblés da Bahia. Beatriz Góes Dantas (1988) aponta a existência deste seguimento nos estados de AL, PE e SE. Outra autora que aborda a construção da identidade nos xangôs recifenses é Rita Segato (1995). Em sua tese, apresenta a contribuição das religiões afro-brasileiras na formação da ideia de pessoa. Para tal fim, realiza uma etnografia densa em alguns terreiros da cidade e propõe um diálogo com os 
arquétipos do psiquiatra Carl Jung.

6. Religião afro-indígena muito popular na região Nordeste, principalmente na região litorânea dos estados de PE, PB, AL e SE.

7. Noite do Dendê é uma festa promovida pela nação Porto Rico na sua comunidade. Nela são celebradas a religiosidade e cultura afro-brasileiras, em especial a afro-pernambucana. Para uma análise sobre o papel desta festa ver Alencar, 2015.

8. Toada da nação Porto Rico, carnaval 2015.

9. Espírito ancestral. Uma pessoa que já passou pela terra, já possuiu matéria.

10. Entrevista concedida em julho de 2015. O maracatu-nação Leão Coroado é o mais antigo em atividade constante. Foi fundado em 1863.

11. Obrigações são oferendas, rituais e sacrifícios realizados para determinadas entidades e situações. Cada orixá e cada trabalho tem suas próprias composições de oferendas.

12. Estamos nos referindo a toda uma gama de rituais específicos que envolvem tambores, calungas, maracatuzeiro/as e entidades (orixás e eguns) no espaço do terreiro, conduzidos por babalorixás ou ialorixás (pais e mães de santo geralmente responsáveis pelo terreiro).

13. Mestre, presidente e babalorixá da nação de maracatu Leão Coroado até 1997, ano de seu falecimento.

14. De forma geral, o método etnográfico caracteriza-se por uma abordagem de vivência junto ao grupo escolhido como interesse de pesquisa. Este estudo valoriza um trabalho qualitativo, densamente descrito e analisado. Também poderia ser enquadrado enquanto processo e resultado produzido.

15. Ariano Suassuna foi o idealizador do Movimento Armorial, que tem como objetivo criar uma arte erudita a partir de elementos da cultura popular do Nordeste brasileiro. Tal movimento procura orientar para esse fim todas as formas de expressões artísticas: música, dança, literatura, artes plásticas, teatro, cinema, arquitetura, entre outras expressões.

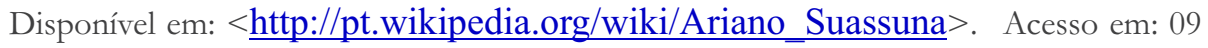
jun. 2014.

16. Trecho extraído do Manifesto Caranguejos com Cérebro escrito em julho de 1992, pelo jornalista músico pernambucano Fred Zero Quatro, fundador da banda Mundo Livre S/A.

17. Desde 2002, o Arrasta Ilha tem por objetivo difundir a cultura do maracatu-nação de baque virado. Além disso, o trabalho do grupo desde a sua fundação tem contribuído para difusão de outras manifestações culturais como o boi de mamão, o circo, o coco de roda e o afoxé. As apresentações acontecem geralmente na rua, em forma de cortejo, como no carnaval, mas o grupo também realiza apresentações de palco.

18. Estas palavras são comuns no vocabulário do povo de santo, sendo o aiyê referendado como a terra, morada das pessoas encarnadas, plano terreno; sendo orúm a outra metade, a morada dos orixás, lugar mítico de onde partiu a expedição de criação da terra.

19. Entrevista concedida em julho de 2015.

20. Oferenda ritual para determinada entidade.

21. Pessoa que toca os ilús/atabaques (instrumento com pele de cabra percutido pelas mãos ou varetas), responsável pela cadência e ritmos tocados para cada orixá. Posição ocupada exclusivamente por homens.

22. Ilú é o equivalente ao atabaque enquanto instrumento sonoro de comunicação com os orixás nas giras do xangô pernambucano. Composto por um corpo (bojo) de madeira, peles de bode presas em sua boca superior e inferior por aros de ferro, estes são ligados um ao outro por uma longa haste de metal, onde na extremidade inferior encontra-se rosca e porca, necessários à afinação do instrumento. Normalmente é tocado com as mãos. Chama a atenção sua base de sustentação feita de madeira em forma de cruz presa permanentemente ao bojo. São objetos sagrados de importância ímpar no ritual.

23. Barracatu é o bar localizado junto à sede da Nação de Maracatu Porto Rico e ao terreiro Ilê Oxóssi Guangoubira, que foi reinaugurado em setembro de 2012.

\section{Referências bibliográficas}


ALENCAR, Alexandra E. V. "É de Nação Nagô!": o Maracatu-Nação como Patrimônio Imaterial Nacional. Tese de doutorado. UFSC, 2015.

ALENCAR, Alexandra E. V. Dançando as novas africanidades: diálogos com os praticantes de maracatu e dança afro em Florianópolis. Dissertação de mestrado. UFSC, 2009.

ANDRADE, Mario de. "O maracatu”. In: Danças Dramáticas do Brasil. Editora Itatiaia, tomo 2. São Paulo, Livraria Martinas, [1934]1959.

ANJOS, José Carlos Gomes dos. No território da linha cruzada: a cosmopolítica afro-brasileira. Porto Alegre: Editora UFRGS/ Fundação Cultural Palmares, 2006.

BARBOSA, Maria Cristina. A Nação de Maracatu Estrela Brilhante de Campo Grande. Monografia apresentada ao curso de especialização em Etnomusicologia da Universidade Federal de Pernambuco, 2001.

BARBOSA, Virgínia. A Reconstrução Musical e Sócio-Religiosa do Maracatu Nação Estrela Brilhante (Recife): Casa Amarela/ Alto José do Pinho. Monografia apresentada ao curso de especialização em Etnomusicologia da Universidade Federal de Pernambuco, 2001.

BASTIDE, Roger. Imagens do Nordeste místico em branco e preto. Rio de Janeiro: O Cruzeiro, 1945.

BASTIDE, Roger. As religiões africanas no Brasil: contribuição a uma sociologia das interpretações de civilizações. Ed. USP, 1971.

BAUMAN, Richard and Charles L. Briggs. Poetics and Performance as Critical Perspectives on Language and Social Life. In: Annual Review of Anthropology V. 19, Bernard J. Siegel, ed. Palo Alto, Annual Reviews, 1990.

CAPONE, Stefania. A busca da África no Candomblé - tradição e poder no Brasil.Rio de Janeiro: Contra Capa Livraria/Pallas, 2009.

CARVALHO, Ernesto I. de. Diálogo de negros, monólogo de brancos: Transformações e apropriações musicais no maracatu de baque virado. Dissertação de mestrado. UFPE, 2007.

COSTA, Francisco A. Pereira da. Folclore Pernambucano. RJ, [1908] 2004.

DANTAS, Beatriz Góis. Vovó nagô e papai branco: usos e abusos da África no Brasil. RJ: Graal, 1988.

DELEUZE, Gilles \& GUATTARI, Felix. Mil Platôs: Capitalismo e esquizofrenia. Vol. 4. SP: Ed. 34, 2011.

FERREIRA, Ascenço. É de Tororó Maracatu. Rio de Janeiro: Livraria-Editora da 
Casa do Estudante do Brasil, 1951.

FERREIRA, Cleison Leite. O Espaço dos Maracatus-Nação de Pernambuco: Território e Representação. Dissertação (Mestrado em Geografia). Programa de PósGraduação em Geografia da UNB, Brasília, 2012.

FREIRE, Paulo. Pedagogia da Autonomia: saberes necessários à prática educativa São Paulo: Paz e Terra, 1996.

FREYRE, Gilberto. Casa grande e senzala: formação da família brasileira sob o regime da economia patriarcal. SP, Global, 2003.

GUERRA-PEIXE, César. Maracatus do Recife. Recife: Fundação de Cultura da Cidade do Recife: São Paulo: Irmãos Vitale, 1980.

GUILLEN, Isabel Cristina Martins. Maracatus-Nação: História e Historiografia. In: Inventário Cultural dos Maracatus Nação. Isabel Cristina Martins Guillen (Org.). Recife: Ed. Universitária da UFPE, 2013.

GOLDMAN, Márcio. Cavalo dos Deuses: Roger Bastide e as transformações das religiões de matriz africana no Brasil. Revista de Antropologia, São Paulo, USP, 2011, V. $54 \mathrm{~N}^{\circ} 1$.

KOLINSKI, Anna Beatriz Zanine. "A minha nação é nagô, a vocês eu vou apresentar" - Mito, simbolismo e identidade na Nação de Maracatu Porto Rico. Dissertação (Mestrado em Antropologia) - Programa de Pós-Graduação em Antropologia da UFPE, Recife, 2011.

KUBRUSLY, Clarisse. A experiência etnográfica de Katarina Real (1927-2006): colecionando maracatus em Recife. Dissertação de mestrado. UFRJ, 2007.

LANGDON, E.J.. A Fixação da Narrativa: Do Mito para a Poética de Literatura Oral. Horizontes Antropológicos. Ano 5, nº 12. Pp. 13-37. Porto Alegre, UFRGS, 1999.

LARA, Larissa Michelle. O sentido ético-estético do corpo na cultura popular. Tese (Doutorado em Educação). Programa de Pós-Graduação em Educação, UNICAMP, São Paulo, 2004.

LEAL, Leonardo Esteves. "Viradas" e "marcações": a participação de pessoas de classe média nos grupos de maracatu de baque virado do Recife - PE. Dissertação (Mestrado em Antropologia) - Programa de Pós-Graduação em Antropologia da UFPE, Recife, 2008.

LIMA, Ivaldo Marciano de França. Maracatus-Nação: Ressignificando Velhas Histórias. Recife: Edições Bagaço, 2005.

LIMA, Ivaldo Marciano de França. Maracatu-nação e Grupos Percussivos: diferenças, conceitos e histórias. In: Inventário cultural dos maracatus nação. Isabel Cristina 
Martins Guillen (Org.). Recife: Ed. Universitária da UFPE, 2013.

MAGGIE, Yvonne. Guerra de orixá: um estudo de ritual e conflito. Jorge Zahar Editor, RJ, [1975] 2001.

MARTINS, Leda. Afrografias da memória: o Reinado do Rosário de Jatobá. São Paulo: Perspectiva ; Belo Horizonte: Mazza Edições, 1997 -(Coleção Perspectiva).

MOTTA, Roberto. Tempo e milênio nas religiões afrobrasileira. In: Anais do XXIV Encontro Anual da Anpocs, 2000.

OLIVEIRA, Jailma Maria. Rainhas, mestres e tambores:gênero, corpo e artefatos no maracatu nação pernambucano. Dissertação (Mestrado em Antropologia). Programa de Pós-graduação em Antropologia da UFPE, Recife, 2011.

PEREIRA, Edimilson de A; e GOMES, Núbia P. de M. "Inumeráveis cabeças. Tradições Afro-Brasileiras e Horizontes da Contemporaneidade." In Brasil AfroBrasileiro. Maria Nazareth S. Fonseca, organizadora. Belo Horizonte: Autêntica, 2000.

REAL, Katarina. O Folclore no carnaval do Recife. Publicações da Campanha de Defesa do Folclore Brasileiro. Ministério da Educação e da Cultura. Rio de Janeiro, [1965] 1990.

REAL, Katarina. Eudes: o rei do maracatu. Recife: Fundação Joaquim Nabuco, Editora Massangana, 2001.

REIS, Demian Moreira. Dança do Quilombo: os significados de uma tradição. AfroAsia (UFBA), Salvador- Bahia, v. n.17, p. 159-171, 1996.

ROCHA, Agenor M. Os candomblés Antigos do Rio de Janeiro. RJ: Topbooks, 1994.

RODRIGUES, Raimundo Nina. Os Africanos no Brasil. São Paulo, Companhia Editora Nacional, 1932.

SANTOS, Juana Elbein dos. Os Nagô e a morte: Pàde, Àsèsè e o culto do Égun na Bahia.Traduzido pela Universidade Federal da Bahia. 14a ed. - Petrópolis, Vozes, 2012.

SANTANA, Paola Verri de. Maracatus: a centralidade da periferia. Tese (Doutorado em Geografia) - Programa de Pós-Graduação em Geografia, USP, São Paulo: 2006.

SEGATO, Rita Laura. Santos e daimones: o politeísmo afro-brasileiro e a tradição arquetipal. Brasília: Editora Universidade de Brasília, 1995.

SETTE, Mario. Arruar - Histórias pitorescas do Recife Antigo. Rio de Janeiro: Livraria Editora da Casa do Estudante do Brasil, 1948. 
SETTTE, Mario. Maxabombas e maracatus. Recife: Livraria Universal, $2^{\mathrm{a}}$ ed, 1938.

VAREJÃO, Lucilo. Reis de Maracatu. In: MAIOR, Mário Souto; Silva, Leonardo Dantas. Antologia do Carnaval do Recife. Recife: Editora Massagana, 1991.

WULF, Christoph. Homo Pictor: imaginação, ritual e aprendizado mimético no mundo globalizado. Tradução: Vinicius Spricigo - São Paulo: Hedra, 2013.

TRINDADE-SERRA, Ordep José. Águas do rei. Petrópolis, RJ: Vozes; Rio de Janeiro: Koinonia, 1995.

TURNER, Victor W. O processo ritual: estrutura e antiestrutura. Petrópolis, RJ: Vozes, 2013. 